\title{
Hormone receptor status may impact the survival benefit of surgery in stage IV breast cancer: a population-based study
}

\author{
Yinuo Tan ${ }^{1,2, *}$, Xiaofen Lii, ${ }^{2}$, Haiyan Chen ${ }^{1,2}$, Yeting Hu ${ }^{1,2}$, Mengjie Jiang ${ }^{2,3}$, Jianfei \\ $\mathrm{Fu}^{4}$, Ying Yuan ${ }^{2,3}$ and Kefeng Ding ${ }^{1,2}$ \\ ${ }^{1}$ Department of Surgical Oncology, 2nd Hospital of Zhejiang University School of Medicine, Hangzhou, P.R. China \\ ${ }^{2}$ Cancer Institute, Key Laboratory of Cancer Prevention and Intervention, China National Ministry of Education, Key Laboratory \\ of Molecular Biology in Medical Sciences, Hangzhou, Zhejiang Province, China, and The Second Affiliated Hospital, Zhejiang \\ University School of Medicine, Hangzhou, P.R. China \\ ${ }^{3}$ Department of Medical Oncology, 2nd Hospital of Zhejiang University School of Medicine, Hangzhou, P.R. China \\ ${ }^{4}$ Department of Oncology, Jinhua Central Hospital, Jinhua, P.R. China \\ * These authors have contributed equally to this work \\ Correspondence to: Kefeng Ding, email: dingkefeng@zju.edu.cn
}

Ying Yuan, email: yuanying1999@zju.edu.cn

Keywords: metastatic breast cancer, surgery, prognosis, SEER

Received: November 13,2015 Accepted: May 29, 2016

Published: August 11, 2016

\section{ABSTRACT}

Introduction: The role of surgery in stage IV breast cancer is controversial. We used the Surveillance, Epidemiology, and End Results database to explore the impact of surgery on the survival of patients with stage IV breast cancer.

Methods: In total, 10,441 eligible stage IV breast cancer patients from 2004 to $\mathbf{2 0 0 8}$ were included. They were divided into four groups as follows: Ro group (patients who underwent primary site and distant metastatic site resection), primary site resection group, metastases resection group, and no resection group.

Results: The four groups achieved a median survival time (MST) of 51, 43, 31 and 21 months, respectively, $P<0.001$. The Cox proportional hazards model showed that the RO group, primary resection group and metastases resection group had a good survival benefit, with hazard ratios of 0.558 (95\% CI, $0.471-0.661), 0.566$ (95\% $\mathrm{CI}, 0.557-0.625)$ and 0.782 (95\% CI, 0.693-0.883), respectively. In the hormone receptor (HR)-positive population, the RO group (MST = $66 \mathrm{~m}, 5$-year OS $=54.1 \%$ ) gained an additional survival benefit compared with the primary resection group (MST = $52 \mathrm{~m} ; 5$-year OS $=44.9 \% ; P<0.001$ ). The metastases resection group (MST $=38 \mathrm{~m}$; 5-year OS $=31.7 \%$ ) survived longer than the no resection group (MST = $28 \mathrm{~m} ; 5$-year OS $=22.0 \% ; P<0.001$ ). In the HR-negative population, the RO group and primary resection group had a similar survival $(P=0.691)$, and the metastases resection group had a similar outcome to that of the no resection group $(P=0.526)$.

Conclusion: Patients who underwent surgery for stage IV breast cancer showed better overall survival than the no resection group. Cytoreductive surgery could provide a survival benefit in HR+ stage IV breast cancer; however, in the HRpopulation, extreme caution should be exercised when considering surgery.

\section{INTRODUCTION}

Traditionally, metastatic breast cancer would be considered an incurable disease, in which the systemic approaches were recommended. However, it has been debated for years whether surgery could actually attain a survival benefit in metastatic breast cancer. Since 2002, several retrospective clinical studies have shown that primary tumor resection is correlated with significantly increased survival in patients with primary metastatic 
Table 1: Clinical and pathological features of the study population

\begin{tabular}{|c|c|c|c|c|c|c|}
\hline \multirow[b]{2}{*}{ Variance } & \multicolumn{5}{|c|}{\begin{tabular}{|l|} 
No. $(\%)$ of patients \\
\end{tabular}} & \multirow[b]{2}{*}{$P$ valuc } \\
\hline & $\begin{array}{l}\text { R0 resection } \\
(n=272)\end{array}$ & $\begin{array}{l}\text { Primary } \\
\text { resection } \\
(n=4025)\end{array}$ & $\begin{array}{l}\text { Metastases resection } \\
(n=409)\end{array}$ & $\begin{array}{l}\text { No resection } \\
(n=5735)\end{array}$ & $\begin{array}{l}\text { Total } \\
(n=10441)\end{array}$ & \\
\hline Age & & & & & & $<0.001$ \\
\hline$\leq 45$ years & $56(20.6)$ & $713(17.7)$ & $67(16.4)$ & $664(11.6)$ & $1500(14.4)$ & \\
\hline$>45$ years & $216(79.4)$ & $3312(82.3)$ & $342(83.6)$ & $5071(88.4)$ & 8941 (85.6) & \\
\hline Race & & & & & & 0.025 \\
\hline White & $222(81.6)$ & $3098(77.0)$ & $322(78.7)$ & $4363(76.1)$ & 8005 (76.7) & \\
\hline Black & $33(12.1)$ & $622(15.5)$ & $64(15.6)$ & $989(17.2)$ & $1708(16.4)$ & \\
\hline Other & $15(5.5)$ & $296(7.4)$ & $22(5.4)$ & $359(6.3)$ & $692(6.6)$ & \\
\hline Unknown & $2(0.7)$ & $9(0.2)$ & $1(0.2)$ & $24(0.4)$ & $36(0.3)$ & \\
\hline Grade & & & & & & $<0.001$ \\
\hline Well & $19(7.0)$ & $262(6.5)$ & $19(4.6)$ & $284(5.0)$ & $584(5.6)$ & \\
\hline Moderate & $98(36.0)$ & $1291(32.1)$ & $87(21.3)$ & $1460(25.5)$ & $2936(28.1)$ & \\
\hline Poor & $121(44.5)$ & $2146(53.3)$ & $96(23.5)$ & $1867(32.6)$ & $4230(40.5)$ & \\
\hline Unknown & $34(12.5)$ & $326(8.1)$ & $207(50.6)$ & $2124(37.0)$ & $2691(25.8)$ & \\
\hline Stage T & & & & & & $<0.001$ \\
\hline T0 & $5(1.8)$ & $4(0.1)$ & $32(7.8)$ & $165(2.9)$ & $206(2.0)$ & \\
\hline $\mathrm{T} 1$ & $55(20.2)$ & $611(15.2)$ & $44(10.8)$ & $436(7.6)$ & $1146(11.0)$ & \\
\hline $\mathrm{T} 2$ & $84(30.9)$ & $1382(34.3)$ & $69(16.9)$ & $950(16.6)$ & $2485(23.8)$ & \\
\hline T3 & $35(12.9)$ & $610(15.2)$ & $21(5.1)$ & $474(8.3)$ & $1140(10.9)$ & \\
\hline $\mathrm{T} 4$ & $71(26.1)$ & $1217(30.2)$ & $96(23.5)$ & $1984(34.6)$ & $3368(32.3)$ & \\
\hline Tx & $22(8.1)$ & $201(5.0)$ & $147(35.9)$ & $1726(30.1)$ & $2096(20.1)$ & \\
\hline Stage N & & & & & & $<0.001$ \\
\hline 0 & $56(20.6)$ & $787(19.6)$ & $100(24.4)$ & $1271(22.2)$ & $2214(21.2)$ & \\
\hline 1 & $80(29.4)$ & $1308(32.5)$ & $116(28.4)$ & $1956(34.1)$ & $3460(33.1)$ & \\
\hline 2 & $51(18.8)$ & 745 (18.5) & $21(5.1)$ & $347(6.1)$ & $1164(11.1)$ & \\
\hline 3 & $58(21.3)$ & $877(21.8)$ & $30(7.3)$ & $502(8.8)$ & $1467(14.1)$ & \\
\hline $\mathrm{NX}$ & $27(9.9)$ & $307(7.7)$ & $142(34.7)$ & $1659(28.9)$ & $2136(20.5)$ & \\
\hline Radiation & & & & & & $<0.001$ \\
\hline Done & 135 (49.6) & $1703(42.3)$ & $163(39.9)$ & $1685(29.4)$ & $3686(35.5)$ & \\
\hline None & $127(46.7)$ & $2216(55.1)$ & $219(53.5)$ & 3979 (69.4) & $6541(62.6)$ & \\
\hline Unknown & $10(3.7)$ & $106(2.6)$ & $27(6.6)$ & $71(1.2)$ & $214(2.0)$ & \\
\hline ER & & & & & & $<0.001$ \\
\hline Positive & $180(66.2)$ & 2589 (64.3) & $248(60.6)$ & 3403 (59.3) & $6420(61.5)$ & \\
\hline Negative & $75(27.6)$ & $1156(28.7)$ & $78(19.1)$ & $1241(21.6)$ & $2550(24.4)$ & \\
\hline Unknown & $17(6.3)$ & $280(7.0)$ & $83(20.3)$ & $1091(19.0)$ & $1471(14.1)$ & \\
\hline PR & & & & & & $<0.001$ \\
\hline Positive & $148(54.4)$ & 1990 (49.4) & $172(42.1)$ & $2574(44.9)$ & $4884(46.8)$ & \\
\hline Negative & $104(38.2)$ & $1706(42.4)$ & $144(35.2)$ & $1953(34.1)$ & 3907 (37.4) & \\
\hline Unknown & $20(7.4)$ & $329(8.2)$ & $93(22.7)$ & $1208(21.1)$ & $1650(15.8)$ & \\
\hline HR & & & & & & $<0.001$ \\
\hline $\mathrm{HR}+$ & $184(67.6)$ & $2646(65.7)$ & $252(61.6)$ & $3472(60.5)$ & $6554(62.8)$ & \\
\hline HR- & $70(25.7)$ & $1095(27.2)$ & $74(18.1)$ & $1162(20.3)$ & $2401(23.0)$ & \\
\hline Unknown & $18(6.6)$ & $284(7.1)$ & $83(20.3)$ & $1101(19.2)$ & $1486(14.2)$ & \\
\hline Metastatic site & & & & & & $<0.001$ \\
\hline $\begin{array}{l}\text { Distant Lymph } \\
\text { node }\end{array}$ & 48 (17.6) & $334(8.3)$ & $22(5.4)$ & $192(3.3)$ & $596(5.7)$ & \\
\hline
\end{tabular}




\begin{tabular}{|l|l|l|l|l|l|l|}
\hline $\begin{array}{l}\text { Designated } \\
\text { organs }^{\mathrm{a}}\end{array}$ & $94(34.6)$ & $1709(42.5)$ & $167(40.8)$ & $2393(41.7)$ & $4363(41.8)$ & \\
\hline Other organs & $78(28.7)$ & $1541(38.3)$ & $130(31.8)$ & $2164(37.7)$ & $3913(37.5)$ & \\
\hline Multiple ${ }^{\mathrm{b}}$ & $44(16.2)$ & $373(9.3)$ & $81(19.8)$ & $913(15.9)$ & $1411(13.5)$ & \\
\hline Unknown $^{8}$ & $8(2.9)$ & $68(1.7)$ & $9(2.2)$ & $73(1.3)$ & $158(1.5)$ & \\
\hline
\end{tabular}

$\mathrm{HR}+$ was defined as ER+ or PR+. HR- was defined as both ER- and PR-.

a Designated organs, metastasis in the following organs: adrenal (suprarenal) gland, bone, other than the adjacent rib, contralateral (opposite) breast, lung, ovary, satellite nodule(s) in skin other than the primary breast.

${ }^{\mathrm{b}}$ Multiple mean metastases in at least two of the above sites.

breast cancer[1];however, other studies have indicated that surgery in metastatic breast cancer does not translate into a significant survival benefit. Breast cancer has clinical and biological heterogeneity, and the major subtypes of breast cancer are classified by three markers: estrogen receptor (ER), progesterone receptor (PR), and human epidermal growth factor 2-neu (HER2). Many recent findings have indicated that hormone receptor (HR) positivity may correlate with a better outcome of the breast cancer patient. It has been rarely studied whether surgery for metastatic breast cancer with different hormone receptor status could achieve a different survival benefit. Thus, we conducted a retrospective population-based study to explore the survival benefit of surgery in stage IV breast cancer using the Surveillance, Epidemiology, and End Results (SEER) program data.

\section{RESULTS}

\section{Clinical and pathological features}

The clinical and pathological features of the study population $(n=10,441)$ are shown in Table 1 . The median OS was 29.0 months. Both primary site and distant metastatic site resections were performed in $272(2.61 \%)$

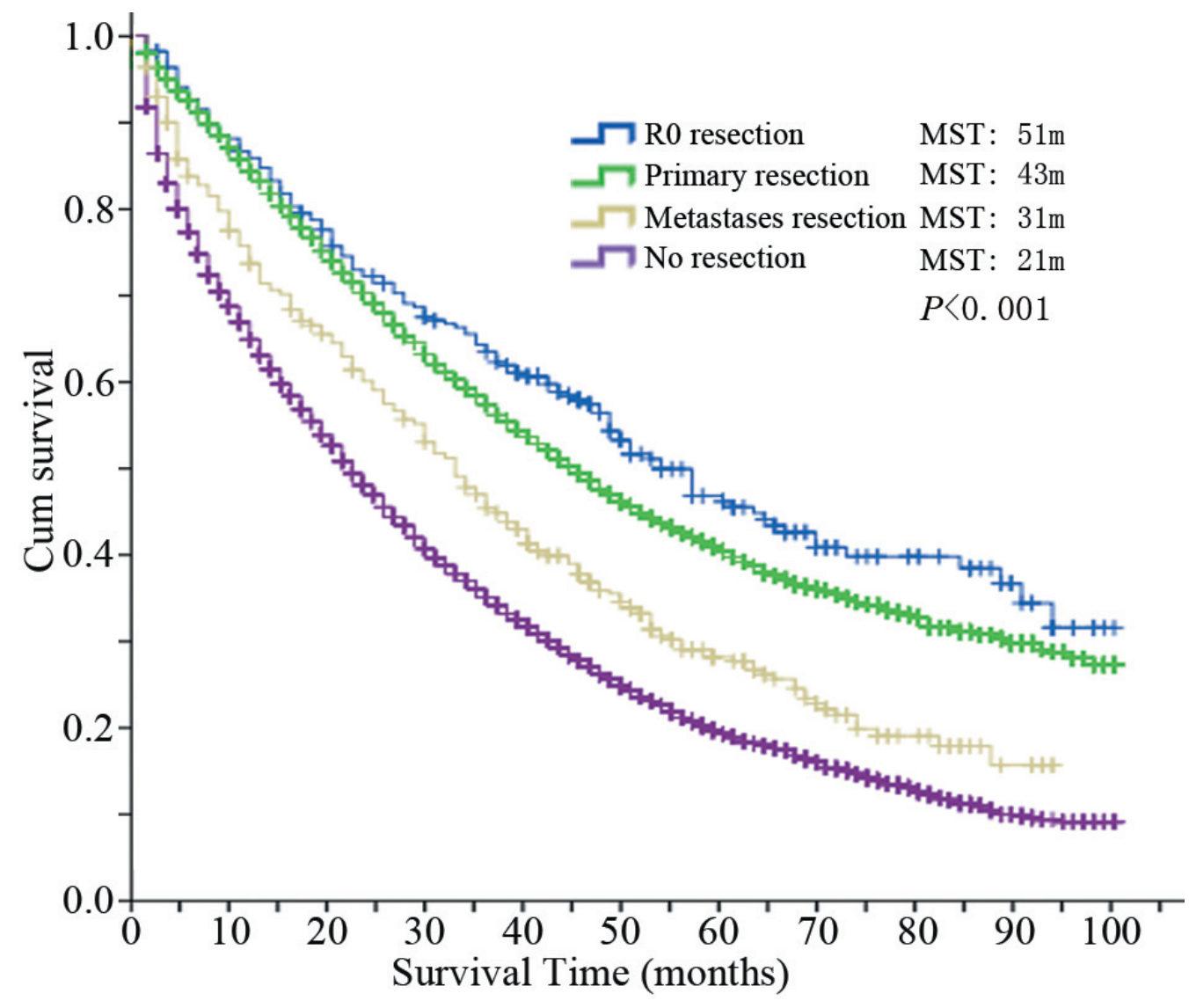

Figure 1: Overall survival curves of the four groups. 
Table 2: Stratified analyses results of median survival time

\begin{tabular}{|c|c|c|c|c|c|c|}
\hline Variance & R0 resection & $\begin{array}{l}\text { Primary } \\
\text { resection }\end{array}$ & \begin{tabular}{|l|} 
Metastases \\
resection
\end{tabular} & No resection & Total & $P$ value $^{\text {a }}$ \\
\hline \multicolumn{7}{|l|}{ Age } \\
\hline$\leq 45$ years & 57 & 51 & 49 & 26 & 39 & $<0.001$ \\
\hline$>45$ years & 51 & 41 & 29 & 20 & 28 & $<0.001$ \\
\hline \multicolumn{7}{|l|}{ Race } \\
\hline White & 54 & 44 & 31 & 22 & 31 & $<0.001$ \\
\hline Black & 25 & 30 & 26 & 15 & 20 & $<0.001$ \\
\hline Other & 84 & 58 & 64 & 24 & 40 & $<0.001$ \\
\hline \multicolumn{7}{|l|}{ Grade } \\
\hline Well & NA & 70 & 50 & 33 & 45 & $<0.001$ \\
\hline Moderate & 66 & 58 & 34 & 28 & 41 & $<0.001$ \\
\hline Poor & 35 & 34 & 22 & 18 & 26 & $<0.001$ \\
\hline \multicolumn{7}{|l|}{ Stage T } \\
\hline T0 & 34 & 34 & $\mathrm{NA}$ & 24 & 30 & 0.006 \\
\hline T1 & 54 & 62 & 38 & 25 & 42 & $<0.001$ \\
\hline $\mathrm{T} 2$ & 66 & 52 & 33 & 27 & 40 & $<0.001$ \\
\hline T3 & NA & 37 & 45 & 26 & 34 & $<0.001$ \\
\hline $\mathrm{T} 4$ & 33 & 32 & 16 & 18 & 23 & $<0.001$ \\
\hline \multicolumn{7}{|l|}{ Radiation } \\
\hline Done & 54 & 47 & 31 & 20 & 33 & $<0.001$ \\
\hline None & 50 & 39 & 31 & 22 & 27 & $<0.001$ \\
\hline \multicolumn{7}{|l|}{ HR } \\
\hline $\mathrm{HR}+$ & 66 & 52 & 38 & 28 & 38 & $<0.001$ \\
\hline HR- & 18 & 24 & 12 & 12 & 17 & $<0.001$ \\
\hline \multicolumn{7}{|l|}{ Metastatic site } \\
\hline $\begin{array}{l}\text { Distant lymph } \\
\text { node }\end{array}$ & NA & NA & 33 & 27 & 62 & $<0.001$ \\
\hline $\begin{array}{l}\text { Designated } \\
\text { organsb }\end{array}$ & 46 & 42 & 32 & 23 & 31 & $<0.001$ \\
\hline Other organs & 48 & 43 & 31 & 20 & 28 & $<0.001$ \\
\hline Multiplec & 38 & 26 & 18 & 17 & 21 & $<0.001$ \\
\hline Total & 51 & 43 & 31 & 21 & 29 & $<0.001$ \\
\hline
\end{tabular}

NA, not available.

a Comparison among the four groups.

b Designated organs, metastasis in the following organs: adrenal (suprarenal) gland, bone, other than the adjacent rib, contralateral (opposite) breast, lung, ovary, satellite nodule(s) in skin other than the primary breast.

${ }^{\mathrm{c}}$ Multiple mean metastases in at least two of the above sites

patients (R0 group), 4,025 patients (38.55\%) underwent primary site resection only, 409 patients (3.92\%) underwent metastases resection only, and 5,735 patients $(54.93 \%)$ had no surgery. The characteristics of the HR+ and HR-populations are shown in supplement table 1.

\section{Influence of surgery on the overall outcome}

According to the follow-up results, 7,125 events (breast cancer-specific deaths) were observed. From the Kaplan-Meier survival curves for these four groups, which are shown in Figure 1, the R0 group showed the best overall survival outcome with a median survival time (MST) of 51 months, followed by the primary resection group (MST $=43$ months) and metastases resection group (MST $=31$ months). The no resection group achieved an MST of 21 months. The difference among the four groups was significant $(P<0.001)$. 
Table 3: Results of multivariate analysis using the Cox proportional hazards model

\begin{tabular}{|c|c|c|c|}
\hline Variance & $P$ value & Hazard ratio & 95.0\% Confidence interval \\
\hline \multicolumn{4}{|l|}{ Age } \\
\hline$\leq 45$ years & & 1 & \\
\hline$>45$ years & $<0.001$ & 1.320 & $1.231-1.416$ \\
\hline \multicolumn{4}{|l|}{ Race } \\
\hline White & & 1 & \\
\hline Black & $<0.001$ & 1.280 & $1.204-1.362$ \\
\hline Other & $<0.001$ & 0.797 & $0.719-0.882$ \\
\hline \multicolumn{4}{|l|}{ Grade } \\
\hline Well & & 1 & \\
\hline Moderate & 0.131 & 1.097 & $0.973-1.237$ \\
\hline Poor & $<0.001$ & 1.440 & $1.278-1.622$ \\
\hline \multicolumn{4}{|l|}{ Stage T } \\
\hline $\mathrm{T}^{\mathrm{a}}{ }^{\mathrm{a}}$ & & 1 & \\
\hline $\mathrm{T} 2$ & 0.341 & 1.046 & $0.954-1.147$ \\
\hline T3 & 0.006 & 1.163 & $1.045-1.294$ \\
\hline T4 & $<0.001$ & 1.384 & $1.266-1.512$ \\
\hline \multicolumn{4}{|l|}{ Radiation } \\
\hline Done & & 1 & \\
\hline None & 0.847 & 0.995 & $0.946-1.046$ \\
\hline \multicolumn{4}{|l|}{ HR } \\
\hline Positive & & 1 & \\
\hline Negative & $<0.001$ & 1.714 & 1.616-1.817 \\
\hline \multicolumn{4}{|l|}{ Surgery } \\
\hline No resection & & 1 & \\
\hline $\mathrm{R} 0$ resection & $<0.001$ & 0.558 & $0.471-0.661$ \\
\hline Primary resection & $<0.001$ & 0.590 & $0.557-0.625$ \\
\hline Metastases resection & $<0.001$ & 0.782 & $0.693-0.883$ \\
\hline \multicolumn{4}{|l|}{ Metastatic site } \\
\hline Distant lymph node & & 1 & \\
\hline Designated organs $^{b}$ & $<0.001$ & 1.838 & $1.622-2.083$ \\
\hline Other organs & $<0.001$ & 1.839 & $1.622-2.084$ \\
\hline Multiple $^{c}$ & $<0.001$ & 2.245 & $1.962-2.565$ \\
\hline
\end{tabular}

a T0 merged into T1 when doing Cox multivariate analysis

b Designated organs, metastasis in the following organs: adrenal (suprarenal) gland, bone, other than the adjacent rib, contralateral (opposite) breast, lung, ovary, satellite nodule(s) in skin other than the primary breast.

${ }^{\mathrm{c}}$ Multiple mean metastases in at least two of the above sites.

\section{Subgroup analysis of overall survival}

The stratified analyses based on age at diagnosis, race, grade, tumor stage, radiation, HR status and metastatic site were conducted to explore the differences among the four groups and to determine which subgroup would benefit most from surgery. The survival results of each subgroup are shown in Table 2. It is obvious that the three groups with surgery achieved better MST than the no resection group in each subgroup.

\section{Multivariate analysis using the Cox proportional hazards model}

The results of the multivariate analysis using the Cox proportional hazards model are shown in Table 3. Age over 45 years, black race, poor grade, T3/T4 stage, metastases in organs and HR- status were independently associated with decreased OS, while other race and the three surgery groups were independently associated with increased OS. Compared with the no resection group, the 
Table 4: Median survival time and 5-year overall survival of the four groups based on different hormone receptor status

\begin{tabular}{|l|l|l|l|l|l|l|l|l|}
\hline \multicolumn{4}{|c|}{ HR+ } & \multicolumn{3}{c|}{ HR- } \\
\hline & MST & 5-year OS & $\boldsymbol{P}$ value* & $\boldsymbol{P}$ value\# & MST & 5-year OS & $\boldsymbol{P}$ value* & $\boldsymbol{P}$ value\# \\
\hline R0 resection & $66 \mathrm{~m}$ & $54.1 \%$ & $<0.001$ & 0.011 & $18 \mathrm{~m}$ & $26.7 \%$ & 0.002 & 0.691 \\
\hline $\begin{array}{l}\text { Primary } \\
\text { resection }\end{array}$ & $52 \mathrm{~m}$ & $44.9 \%$ & $<0.001$ & & $24 \mathrm{~m}$ & $25.0 \%$ & $<0.001$ & \\
\hline $\begin{array}{l}\text { Metastases } \\
\text { resection }\end{array}$ & $38 \mathrm{~m}$ & $31.7 \%$ & $<0.001$ & $<0.001$ & $12 \mathrm{~m}$ & $6.8 \%$ & 0.526 & $<0.001$ \\
\hline No resection & $28 \mathrm{~m}$ & $22.0 \%$ & & $<0.001$ & $12 \mathrm{~m}$ & $11.8 \%$ & & $<0.001$ \\
\hline
\end{tabular}

*Compared with the no resection group; \# compared with the primary resection group; ER, estrogen receptor; PR, progesterone receptor; HR+, ER+ or PR+; HR-, both ER- and PR-. OS, overall survival rate.

R0 group showed the best hazard ratio of $0.558(95 \% \mathrm{CI}$, 0.471-0.661), the primary resection group and metastases resection group also had a good survival benefit with a hazard ratio of $0.590(95 \% \mathrm{CI}, 0.557-0.625)$ and 0.782 (95\% CI, 0.693-0.883).

\section{Different HR status shows a different survival benefit from surgery}

The MST and 5-year OS of the four groups based on different HR status are shown in Table 4. The corresponding Kaplan-Meier survival curves are shown in Figure 2. In the HR+ population, the survival of each group with surgery, including the R0 resection group $(\mathrm{MST}=66 \mathrm{~m} ; 5$-year OS $=54.1 \%)$, primary resection group (MST $=52 \mathrm{~m} ; 5$-year OS $=44.9 \%$ ) and metastases

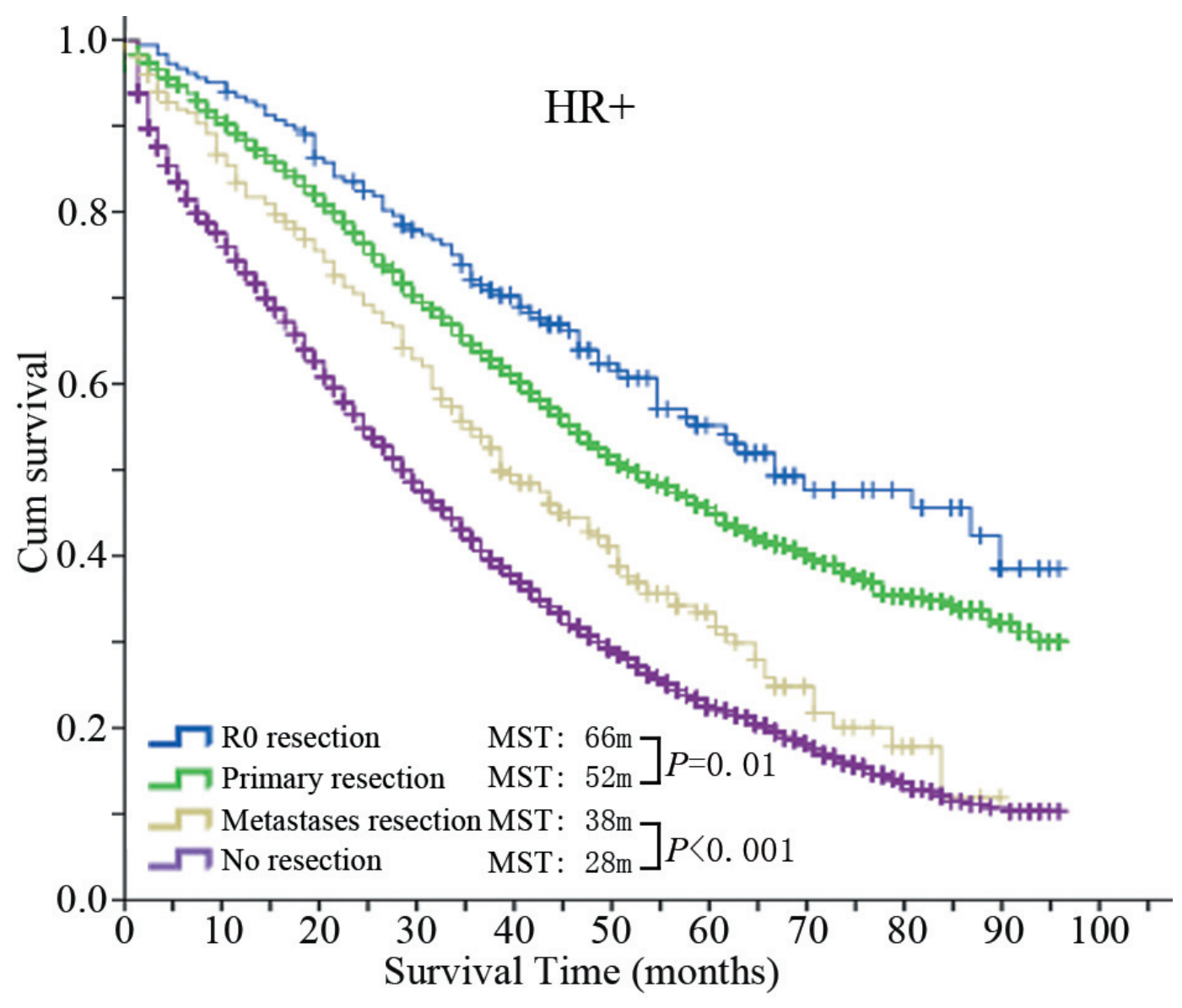

Figure 2: Kaplan-Meier survival curves of the four groups in the HR+ population. 
resection group $(\mathrm{MST}=38 \mathrm{~m}$; 5-year $\mathrm{OS}=31.7 \%)$ were all significantly longer than the no resection group (MST $=28 \mathrm{~m} ; 5$-year OS $=22.0 \%)(P$ values were all $<0.001)$. Furthermore, the R0 group gained an additional survival benefit compared with the primary resection group $(P$ value $<0.001)$. On the other hand, in the HR-population, the survivals of the R0 group (MST $=18 \mathrm{~m}$; 5-year OS = $26.7 \%)$ and primary resection group $(\mathrm{MST}=24 \mathrm{~m}$; 5-year $\mathrm{OS}=25.0 \%$ ) were both significantly longer than the no resection group (MST $=12 \mathrm{~m} ; 5$-year $\mathrm{OS}=11.8 \%$ ) but not the metastases resection group $(\mathrm{MST}=12 \mathrm{~m}, 5$-year $\mathrm{OS}=6.8 \%)(P=0.526)$. Furthermore, the R0 group did not achieve a better survival benefit compared with the primary resection group $(P=0.691)$.

\section{Univariate and multivariate logistic regression as predictors for surgery}

To assess the interaction of HR positivity and the role of surgery, three surgery groups were merged into one group, the surgery group. Univariate logistic regression analysis (results are shown in supplement table 2) by HR positivity revealed that HR-negative patients were significantly more likely to undergo surgery $(\mathrm{OR}=1.201$; $P<0.001$ ); however, after adjusting for other factors, multivariate analysis (results are shown in supplement table 3) showed that HR positivity was not independently associated with greater or less likelihood of surgery $(P=$ $0.814)$.

\section{DISCUSSION}

The present study showed that a survival gain was observed in operated stage IV breast cancer compared with the no resection group. After adjusting for other confounders, multivariate analysis showed that the three surgery groups were independently associated with increased OS. In the HR+ population, survival was best in the R0 group, and metastases resection somehow gained a survival benefit; however, in the HR-population, no significant benefit was attained in the R0 group compared with the primary resection group; additionally, no significant benefit was achieved in the metastases resection group compared with the no resection group.

Recent advances in chemotherapy, endocrine therapy and targeted therapy have achieved a rapid response and increased survival in most metastatic breast

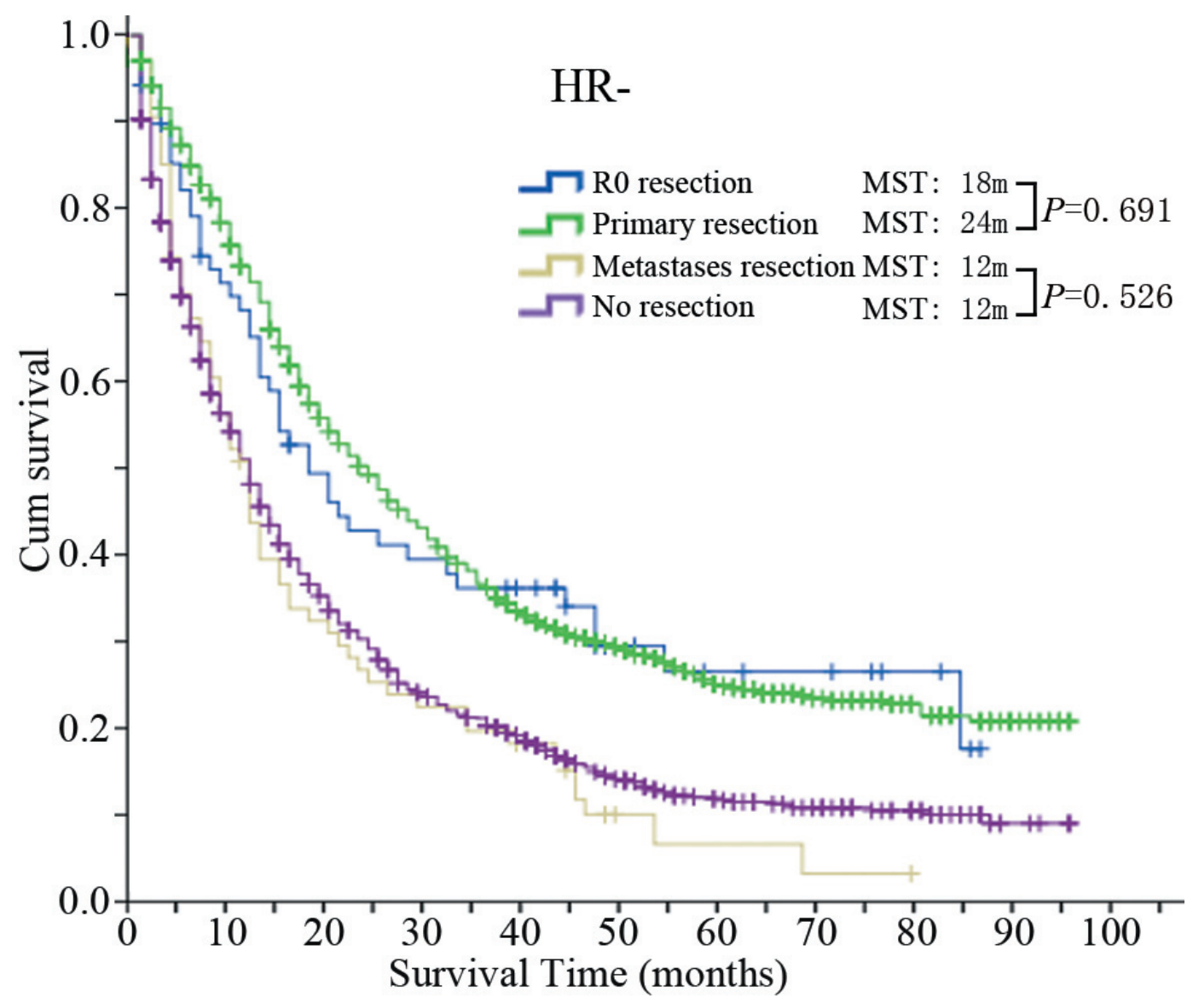

Figure 3: Kaplan-Meier survival curves of the four groups in the HR-population. 
cancer patients[2]; thus, the standard treatment for stage IV breast cancer patients remains medical treatment, and the role of surgery in stage IV breast cancer patients is still controversial[3]. Several positive survival outcomes after surgery, with or without chemotherapy/ endocrine therapy, were associated with a long diseasefree interval after treatment of the primary tumor (12-36 months),[4-14] complete resection of the tumor, $[15,16]$ and ER+ status.[6] Additionally, a meta-analysis of 15 studies demonstrated that surgery of the primary tumor was independently associated with improved survival. [17] There were also some retrospective studies that found surgery to be associated with improved survival in patients with ER/PR-positive disease, while little or no survival benefit was observed in those with triple-negative disease. $[7,13]$ Some people may argue that the survival benefit associated with surgery in these retrospective studies may be due to the selection biases.[18] Therefore, several Phase III randomized controlled trials are being performed to determine whether local therapy would prolong survival in stage IV breast cancer patients.[1, 19] In the study from Tata Memorial Hospital, the median overall survival was 19.2 months in the locoregional treatment group and 20.5 months in the no locoregional treatment group (Hazad ratio $=1.04 ; P=0.79)$, and no subgroup showed a significant survival benefit from surgical excision, including the estrogen receptor/progesterone receptorpositive and -negative groups.[20] Another phase III study from the Turkish Federation of Societies for Breast Disease also demonstrated that the locoregional treatment and no locoregional treatment groups had similar overall survival rates (35\% in the surgery group and $31 \%$ in the no surgery group). In our retrospective study, selection biases may somehow play a role in the survival benefit of these four group comparisons; however, the selection bias may be less between the HR+ population and HR-population. The survival difference between the $\mathrm{R} 0$ resection group and primary resection groups in the $\mathrm{HR}+$ population was significant, but not in the HR- population. Additional survival benefit from metastatic site resection was gained in the HR+ population compared with the HR-population. Similarly, the metastases resection group and no resection group showed different survival outcomes in the HR+ population compared with the HR-population. These re sults may not directly provide evidence to suggest surgical treatment in metastatic breast cancer but may inspire us to explore a more aggressive approach for $\mathrm{HR}+$ breast cancer patients, in whom a survival benefit may be more prone to appear, compared with the HR-population.

The SEER program provided access to a large cohort of patients, making the study results more reliable. However, several limitations remain in our study. First, the information on the patient status was not accessible. There are several important factors associated with the survival of stage IV breast cancer patients, including performance status, number of metastatic sites, HER2 status, endocrine therapy, and chemotherapy. Particularly, the size of the metastases would determine whether it is resectable. Although the SEER program did not include this information, our present study could show, to a certain extent, that cytoreductive surgery could provide a survival benefit in HR+ stage IV breast cancer.

\section{MATERIALS AND METHODS}

\section{Data source}

The SEER program included 17 population-based cancer registries, together comprising approximately $28 \%$ of the total population of the United States.[21-24] Women initially diagnosed with stage IV primary invasive breast cancer from the 2004 to 2008 year were included in the analysis. Patients after year 2008 were not included to ensure a sufficiently long follow-up time.

\section{Patient selection}

Breast cancer patient data were obtained from the SEER Program using Case Listing. Site record ICD-O-3 was limited to the breast. Case patients with sarcomas of the breast (based on the histology codes 8800, 8801, 8805, $8815,8830,8850,8858,8890,8935,8980,8982,8983$, 9120, 9180, 9181, and 9260) were excluded. Multiple primary cancers were also excluded to make accessible analyses of cancer-specific survival. The patients with a survival of less than one month were excluded because such patients may die of surgical complications.

All of the study data-including demographic characteristics, ER, PR status, tumor stage, grade, classification of metastatic site, surgery of primary site and distant site, radiotherapy, cause of death and survival months - were all collected. HER2 status was not collected because it was not available for the cases before year 2010 .

\section{Variables of interest}

Cancer-specific survival was calculated from the date of diagnosis to the date of death related to breast cancer. Death attributed to other causes was considered as censored observation. Cases of grade 4 in histology were combined with cases of grade 3 because the outcome for cases assigned grade 3 or grade 4 was not significantly different.[25] As recorded in the SEER database, the metastatic sites of breast cancer were classified into several groups as follows: 1. distant lymph node(s), 2. metastases in designated organs: adrenal (suprarenal) gland, bone, other than adjacent rib, contralateral (opposite) breast, lung, ovary, satellite nodule(s) in skin other than primary 
breast, 3. metastases in other organs, 4. metastases in at least two of the above sites, 5. unknown.

The ER and PR results were combined and analyzed jointly as hormone receptor (HR) status. HR+ was defined as ER+ or PR+. HR- was defined as both ER- and PR-. ER/ PR borderline case patients (borderline ER: $n=22,0.2 \%$; borderline PR: $n=78,0.7 \%$ ) were defined as unknown. Age at diagnosis was categorized as $\leq 45$ years old versus $>45$ years old. All patients were divided into the following four groups: R0 group (patients who underwent primary site resection and distant metastatic site resection); primary resection group (patients who underwent only primary site resection); metastases resection group (patients who underwent only distant metastatic site resection); and no resection group (no resection was performed on any patient).

\section{Statistical analysis}

The observed differences between the different surgery groups were analyzed statistically by chi-squared test. Univariate analysis of survival was performed using Kaplan-Meier methods, while group comparisons were performed using the log-rank test. Adjusted hazard ratios along with $95 \%$ intervals were calculated using the Cox regression model. Additionally, univariate and multivariate logistic regression analyses were applied to assess factors, especially hormone receptor status, associated with undergoing surgery. Differences were considered to be statistically significant if the $P$ value was less than 0.05 . SPSS 19.0 software (IBM Corp., Armonk, USA) was used for data analysis.

\section{CONFLICTS OF INTEREST} interests.

The authors declared that they have no competing

\section{GRANT SUPPORT}

This research was supported by grants from the National Natural Science Foundation of China (81101580), Key Projects in the National Science \& Technology Pillar Program during the Twelfth Fiveyear Plan Period (2014BAI09B07), the National High Technology Research and Development Program of China (863 Program) (2012AA02A506), the National High Technology Research and Development Program of China (863 Program) (2012AA02A204), and the Training Program of the Major Research Plan of the National Natural Science Foundation of China (91229104).

\section{REFERENCES}

1. Khan SA. De novo Stage IV breast cancer: breast conserving resection of the primary tumor? J Surg Oncol. 2014; 110:51-57.

2. Santa-Maria CA and Gradishar WJ. Changing Treatment Paradigms in Metastatic Breast Cancer: Lessons Learned. JAMA oncology. 2015; 1:528-534; quiz 549.

3. Bleicher RJ, Ruth K, Sigurdson ER, Beck JR, Ross E, Wong YN, Patel SA, Boraas M, Chang EI, Topham NS and Egleston BL. Time to Surgery and Breast Cancer Survival in the United States. JAMA oncology. 2016; 2:330-339.

4. Friedel G, Pastorino U, Ginsberg RJ, Goldstraw P, Johnston M, Pass H, Putnam JB, Toomes $\mathrm{H}$ and International Registry of Lung Metastases LE. Results of lung metastasectomy from breast cancer: prognostic criteria on the basis of 467 cases of the International Registry of Lung Metastases. European journal of cardio-thoracic surgery. 2002; 22:335-344.

5. Simpson R, Kennedy C, Carmalt H, McCaughan B and Gillett D. Pulmonary resection for metastatic breast cancer. The Australian and New Zealand journal of surgery. 1997; 67:717-719.

6. Lanza LA, Natarajan G, Roth JA and Putnam JB, Jr. Longterm survival after resection of pulmonary metastases from carcinoma of the breast. Ann Thorac Surg. 1992; 54:244247; discussion 248.

7. Bafford AC, Burstein HJ, Barkley CR, Smith BL, Lipsitz S, Iglehart JD, Winer EP and Golshan M. Breast surgery in stage IV breast cancer: impact of staging and patient selection on overall survival. Breast cancer research and treatment. 2009; 115:7-12.

8. Cady B, Nathan NR, Michaelson JS, Golshan M and Smith BL. Matched pair analyses of stage IV breast cancer with or without resection of primary breast site. Ann Surg Oncol. 2008; 15:3384-3395.

9. Ruiterkamp J, Voogd AC, Bosscha K, Tjan-Heijnen VC and Ernst MF. Impact of breast surgery on survival in patients with distant metastases at initial presentation: a systematic review of the literature. Breast cancer research and treatment. 2010; 120:9-16.

10. Lang JE, Tereffe W, Mitchell MP, Rao R, Feng L, MericBernstam F, Bedrosian I, Kuerer HM, Hunt KK, Hortobagyi GN and Babiera GV. Primary tumor extirpation in breast cancer patients who present with stage IV disease is associated with improved survival. Ann Surg Oncol. 2013; 20:1893-1899.

11. Nguyen DH, Truong PT, Alexander C, Walter CV, Hayashi E, Christie J and Lesperance M. Can locoregional treatment of the primary tumor improve outcomes for women with stage IV breast cancer at diagnosis? International journal of radiation oncology, biology, physics. 2012; 84:39-45.

12. Ruiterkamp J, Ernst MF, van de Poll-Franse LV, Bosscha K, Tjan-Heijnen VC and Voogd AC. Surgical resection of 
the primary tumour is associated with improved survival in patients with distant metastatic breast cancer at diagnosis. Eur J Surg Oncol. 2009; 35:1146-1151.

13. Neuman HB, Morrogh M, Gonen M, Van Zee KJ, Morrow $\mathrm{M}$ and King TA. Stage IV breast cancer in the era of targeted therapy: does surgery of the primary tumor matter? Cancer. 2010; 116:1226-1233.

14. Rapiti E, Verkooijen HM, Vlastos G, Fioretta G, NeyroudCaspar I, Sappino AP, Chappuis PO and Bouchardy C. Complete excision of primary breast tumor improves survival of patients with metastatic breast cancer at diagnosis. J Clin Oncol. 2006; 24:2743-2749.

15. Livartowski A, Chapelier A, Beuzeboc P, Dierick A, Asselain B, Dartevelle P and Pouillart P. [Surgical excision of pulmonary metastasis of cancer of the breast: apropos of 40 patients]. Bull Cancer. 1998; 85:799-802.

16. McDonald ML, Deschamps C, Ilstrup DM, Allen MS, Trastek VF and Pairolero PC. Pulmonary resection for metastatic breast cancer. Ann Thorac Surg. 1994; 58:15991602.

17. Petrelli F and Barni S. Surgery of primary tumors in stage IV breast cancer: an updated meta-analysis of published studies with meta-regression. Medical oncology. 2012; 29:3282-3290.

18. Leung AM, Vu HN, Nguyen KA, Thacker LR and Bear HD. Effects of surgical excision on survival of patients with stage IV breast cancer. J Surg Res. 2010; 161:83-88.

19. Criscitiello C, Giuliano M, Curigliano G, De Laurentiis M, Arpino G, Carlomagno N, De Placido S, Golshan M and Santangelo M. Surgery of the primary tumor in de novo metastatic breast cancer: To do or not to do? Eur J Surg Oncol. 2015; 41:1288-1292.
20. Badwe R, Hawaldar R, Nair N, Kaushik R, Parmar V, Siddique S, Budrukkar A, Mittra I and Gupta S. Locoregional treatment versus no treatment of the primary tumour in metastatic breast cancer: an open-label randomised controlled trial. The lancet oncology. 2015; 16:1380-1388.

21. Mattes MD, Bhatia JK, Metzger D, Ashamalla H and Katsoulakis E. Breast Cancer Subtype as a Predictor of Lymph Node Metastasis according to the SEER Registry. Journal of breast cancer. 2015; 18:143-148.

22. Iqbal J, Ginsburg O, Rochon PA, Sun P and Narod SA. Differences in breast cancer stage at diagnosis and cancerspecific survival by race and ethnicity in the United States. JAMA. 2015; 313:165-173.

23. Yu KD, Jiang YZ and Shao ZM. Difference between observed and expected number of involved lymph nodes reflects the metastatic potential of breast cancer independent to intrinsic subtype. Oncotarget. 2015; 6:16686-16697. doi: 10.18632/oncotarget.3647.

24. Zeng C, Wen W, Morgans AK, Pao W, Shu XO and Zheng W. Disparities by Race, Age, and Sex in the Improvement of Survival for Major Cancers: Results From the National Cancer Institute Surveillance, Epidemiology, and End Results (SEER) Program in the United States, 1990 to 2010. JAMA oncology. 2015; 1:88-96.

25. Henson DE, Ries L, Freedman LS and Carriaga M. Relationship among outcome, stage of disease, and histologic grade for 22,616 cases of breast cancer. The basis for a prognostic index. Cancer. 1991; 68:2142-2149. 